\title{
Water Governance in a Climate Change World: Appraising Systemic and Adaptive Effectiveness
}

\author{
Lee Godden • Raymond L. Ison • Philip J. Wallis
}

Received: 11 August 2011 / Accepted: 12 August 2011 /

Published online: 1 September 2011

(C) Springer Science+Business Media B.V. 2011

The starting point for this Special Issue is the proposition that climate change is real and anthropogenic factors contribute to the nature and rates of change. In its Climate Change 2007 Synthesis Report, the Intergovernmental Panel on Climate Change (IPCC) identified major consequences for water resources as a result of global warming (IPCC 2007). Adaptation around these impacts will be integral to the evolution of water resources management. However the idea that socio-ecological systems based around water governance will have to adapt over time clearly is not new, nor confined to climate change impacts. Nonetheless, climate change introduces a strong impetus, and under this aegis, we explore in this Special Issue how climate change becomes 'real' in the lives of citizens and the activities of policy makers through the lens of water and its governance, including management. Moreover, '[t]his situation is one of global concern; it raises questions of how water policy makers, policy implementers and researchers will work together to enhance social and institutional innovation for effective implementation of climate change adaptation policies in different countries' (Ison et al. 2011). Not all articles adopt climate change as the core paradigm for analysis, but all explore in various ways the systemic and adaptive effectiveness of water governance in circumstances where change is a central dynamic. To this extent, the articles have a common theme in that adaptation in water governance is best understood 'as a co-evolutionary dynamic' (Collins and Ison 2009).

Globally there are many real-time 'experiments' in water governance under way. It is therefore timely to pause and offer some critical reflections on the viability of these 'experiments' in this Special Issue. We refer to 'water governance experiments' to acknowledge that we are entering a period where there is a need, in a climate changing

All authors contributed equally.

L. Godden

Centre for Resources Energy and Environmental Law, University of Melbourne, Melbourne, Australia

R. L. Ison • P. J. Wallis ( $\square)$

Monash Sustainability Institute, Monash University, Clayton, Australia

e-mail: phil.wallis@monash.edu

R. L. Ison

Communication \& Systems Department, The Open University, Milton Keynes, UK 
world, to pursue an on-going systemic inquiry (Collins and Ison 2010) which continually explores questions of fitness for purpose in what is being done under the rubric of water governance. Past water governance has been characterised by commitments to stationarity (Brown et al., Godden and Kung 2011). Adherence to stationarity, and its enactment in the practices of water resources management, has reified (made into 'things' - see Wenger 1998) many human-invented social technologies in ways that constrain innovation and change and may create path dependencies around existing patterns of water governance (Brown et al.; Harris 2011). This situation is clearly no longer tenable. As yet, it is not clear that we know how to embark on this new trajectory for water governance given the complexity demanded by climate change; we may also lack conceptual, institutional and practical tools to move in new directions. We refer to systemic and adaptive effectiveness as the ability to navigate complexity in a climate changing world and contend that it can't be done with old mental models and business-as-usual practices.

Accordingly, this Special Issue looks to provide new understandings of water resources management as theoretical and practical offerings for embarking on a new trajectory in water governance. Framing water resources management in terms of quantitative water yields, water supply crises, distributive or other technical properties fits within this broader conceptualisation of water governance. It is not, however, a blueprint for a way forward but a tentative quest for new understandings and practices that are more fit-for-purpose. In the papers on offer, Australian experiences dominate but, we contend, from a more social and trans-disciplinary perspective than has historically been the case in reporting on Australia's water governance developments. So far, policy and governance 'choices' about water resources have largely tended to use 'old mental models', largely presented in terms of water supply crises, confronting over-allocation of water, structural adjustment in rural areas, and ensuring sufficient water for food production. Much money and effort has been expended to achieve these water policy objectives in the face of pressing concerns, such as climate change, but on-the ground implementation and effectiveness of water policy decisions still seem a long way off in systemic and adaptive terms.

Issues, such as water sensitive cities, re-use of water, groundwater depletion, aquifer and groundwater contamination, water quality and water/energy interactions are emerging, but to date have received much less governance attention. Importantly, there is a growing acknowledgement that the constraints to achieving adaptive and sustainable water management may lie, not so much in the deficiencies of scientific or technical understanding of water resources, even given climate change, but in a failure to recognise the complexities of institutional, social and cultural change in water governance.

Australian water governance, as featured, thus offers a useful 'learning laboratory' for developing understandings and practices necessary for embarking on new governance trajectories. Australia has needed to urgently respond to widespread climate change impacts, particularly in urban water supply, and in river governance and management for irrigated agriculture (Tisdell 2009). Of course, Australia is not the only relevant context, as exemplified by European experiences (Ison et al. 2011; Mysiak et al. 2010), South Africa (Pollard and du Toit 2011), Canada (Bakker 2007); the USA (Sabatier et al. 2005) and the Mekong Region (Molle et al. 2009). Given the breadth of comparative studies around water governance, there is a strong impetus to share the learning around evolving forms of water governance and to assess new modes from the perspective of systemic and adaptive effectiveness. As De Stefano (2010, p. 2450) suggests, '[i]n a globalized world, the use of comparisons between countries is a powerful policy tool... it makes it possible to identify good management practices, positive supranational trends, the potential need for concerted actions at an international level, or gaps in existing supranational initiatives.' 
Australia has had a history of innovative water management in the past, but as Foerster (2011) notes, '[h]istorical "institutions"-laws, policies, practices — of water management' in areas such as the Murray-Darling Basin, have focused on resource development and exploitation'. Increased pressure on water resources due to the impacts of climate change, as well as growth in major urban centres, is now revealing that previous governance structures may no longer be viable. In Australia, the direct physical ramifications of climate change are apparent - the number of hot days is predicted to increase substantially, particularly in central and north-western Australia. Reduced rainfall, higher evaporation and increased frequency and extent of drought are highly probable for southern Australia. Climate change, combined with natural climatic variability, will exacerbate the frequency and intensity of extreme weather events such as storms cyclones and floods (Garnaut 2011).

Thus, as climate change impacts continue to shift the availability of water resources across the continent, the need for new and innovative water governance structures and mechanisms becomes more pressing. Yet, Wallis and Ison (2011) contend, '[i]nstitutional innovation may be benign, create synergies with existing institutions or cause problems and unintended side effects through institutional complexity'. With so many climate change effects already being felt, Australia has had to begin experimentation with many new and innovative governance approaches but conversely has also reverted to some previous 'dependencies' in water resources management. Overall, Australian water resource 'experiments' under the 'pressure cooker' of climate change provide a fascinating basis in research and policy, and social learning, that can inform other parts of the world in moving towards more systemic and adaptive water governance in an era of climate change. These experiences are complimented in this volume by research from South Africa which faces similar climate change exigencies. This research highlights the need for systemic feedback processes to be operational and timely if governance, and thus adaptation, is to be effective. Ison et al. (2011) address 'wide-spread concerns about the lack of connectivity between science, policy making and implementation.' Enhancing connectivity in water management systems, as well as inventing and using new modalities of practice (Ison et al. 2011) will also need to be achieved for systemic and adaptive effectiveness.

In this vein, one of the significant water governance 'experiments' that Australia has embarked upon over the last decades has been to instigate national water law and policy reform in the face of entrenched regional governance models (Connell 2011). Degradation of water resources and inefficiency of resource use were initial reform drivers, with climate change and perceived water scarcity adding urgency to its implementation. Several articles in this Special Issue offer perspectives on this 'real time' process. Foerster (2011) examines a key platform of the reform agenda in governmental commitments, 'to provide for environmental water... and achieve more ecologically sustainable water allocation and management.' Her analysis identifies, 'a policy problem with high levels of uncertainty, broad and variable temporal and spatial scales, cumulative rather than discreet impacts, and potentially irreversible ecological impacts and related policy urgency'. She concludes, 'that environmental water has such different management imperatives to supplying for consumptive uses and that existing institutional systems have largely evolved to facilitate consumptive use.' It is important to consider, 'how they should be balanced within the one system of management', as it is, 'an area in which institutional capacity to manage adaptively is critical; and collaborative, learning-based approaches to ecosystem management offer great potential.' In a related context, Connell (2011) explores how the Australian federal system creates opportunities for a wide range of actors to influence water policy and management but also engenders stakeholder conflicts. Conflicts have crystallised around the introduction of federal water legislation which has sought to adopt, 'a whole-of 
hydrological systems approach to policy and management' and to institute cross jurisdictional water planning and allocation (Connell 2011). A key mechanism is a national basin-wide plan, although state governments, 'and their subsidiary regional organisations will ultimately implement the water resource plans. Thus, the success of the Australian Water Act 2007 to achieve its goals will depend on maintaining effective cooperation with the states. To ensure effective implementation of the Basin Plan, its designers will have to work with four very different state water management systems.' Recent substantial challenges to a draft basin plan which, in part sought to address water scarcity arising from climate change impacts, highlights the formidable difficulties in developing principles which can be applied across the basin to have, 'a real and positive impact on water management' (Connell 2011).

Critical issues surrounding the implementation of national water reforms is a theme reiterated in the article by Pollard and du Toit (2011). South Africa is well recognised for its water reforms which have included the abolition of riparian rights systems in favour of a 'framework for managing catchment water resources to achieve equity and sustainability'. Such changes have underscored the emergence of a holistic approach where, the 'guiding framework and philosophy for this process is captured in the concept of Integrated Water Resources Management (IWRM)' which implicitly (if not always explicitly) adopts a systemic approach. In an investigation of the Shared Rivers Initiative the authors examine, 'the multiple factors that both constrain or enable compliance with the National Water Act and hence the implementation of IWRM'. In a similar manner to Australia with the impacts of climate change, water resources in the study area have come under increasing pressure. Pollard and du Toit (2011) suggest, 'regulators and users will need to find 'solutions' to oversubscribing the resource. The challenge will be to develop appropriate practices that address unsustainable use - arguably, this can only be done with a certain level of selforganisation within and between the various sectors at different scales.'

By contrast to a focus on collaborative-based reforms, a significant component of national water reform in Australia has been the introduction of market mechanisms; principally water trading in rural irrigation. Harris (2011) examines how water governance in the irrigation sector has undergone substantial change over the last three decades with government centred water allocation processes decreasing in favour of greater reliance on market mechanisms. She identifies that, '[i]nstitutional change will be impacted on by the existence of institutional path dependence created by previous frameworks'. Such institutional path dependence may create rigidity within new institutional arrangements as demonstrated by water markets. She concludes, '[t]he introduction of water markets in Victoria illustrates the impacts of institutional path dependence as regulatory and physical constraints limit possible efficiency gains by dampening or preventing trades. Accordingly, it will constrain the ability for the current water market to maximise efficiency'.

Other studies in the volume also examine the situated impacts of national governance reforms and the constraints they impose. Wallis and Ison (2011) examine, 'one strand of a systemic inquiry focused on the "water managing system" within a nested set of Australian water governance regimes'. These include the Federal statutory organisation responsible for developing and implementing a basin wide water resources plan at the national level, and the Goulburn-Broken Catchment Management Authority at the regional level. Taking institutional complexity as the lens with which to examine this situation, they investigate, 'boundary judgements that are made in formulating institutions and how institutional complexity constrains the effectiveness of agencies involved in the water managing system and how they deal with it.' Their findings suggest that climate change responses by 
government, add to institutional complexity, which 'inadvertently threatens the adaptive capacity of water managing organisations by undermining relational capital.'

While governments have added layers of institutional complexity to address rural water scarcity impacts under climate change, Godden and Kung (2011) identify a lack of institutional and policy attention to enhanced flood risk in water law and policy reforms. Legal models for flood risk embed and enact pre-climate change responses by privileging the 1:100 year flood event standard in water law, land-use planning and associated governance structures. They conclude that law and policy must become more proactive in managing for flood risk under climate change by instituting a range of strategic planning amendments and in facilitating autonomous and iterative responses to flood risk which capture local adaptation initiatives.

The significant barriers that exist to adaptation initiatives in urban water governance is a problem identified by Brown et al. (2011). Concurrently though, they highlight the transformative potential that a reassessment of centralised urban water services can provide. In an article drawn from long-standing research into the transformation of water governance in cities, the authors suggest, "the conventional urban water management approach is highly unsuited to addressing current and future uncertainties and complexities (i.e. climate change predictions including extreme weather events, growing demand for water and increasing populations)'. In a comparison of Australian and UK experience, they suggest, 'total water cycle management' offers a more resilient approach to urban water management, but transformative change is difficult as political risk, professional agency fear, and a lack of a hybrid governance approach, result in path dependencies. Thus there is a 'lock-in' to the, 'current large-scale, centralised infrastructure model' which means the sector is unable to accommodate new technologies and management approaches beyond niche projects.

The challenges in breaking with established patterns of water resources management that inform many of the articles, notwithstanding the impetus of climate change, reinforces the existence of the many human invented social technologies that constrain innovation and change (Ison et al. 2011). Equally though an awareness that water resources management is situated within a socio-ecological system strengthens the view that, 'reconceptualisations of water catchments as coupled social-, or socio-ecological systems hold promise but also make new demands on understanding the nature of the research-policy-practice relationship'.

This Special Issue thus charts demands for new understanding of the research-policypractice relationship for water governance. Given the challenges of water managing and the imperatives of climate change adaptation, it reinforces the importance of social learning and the imperative of ensuring that the implementation of climate change adaptation is real, 'i.e. grounded in situations appropriately framed in context sensitive, yet theoretically rigorous ways' (Ison et al. 2011).

This Special Issue arises from ongoing collaborative scholarship by the editors. We would like to acknowledge a number of key people who helped bring this Special Issue to completion. Firstly, we thank the reviewers for their comprehensive and high-quality reviews that helped to improve many of the articles. We thank the contributors for their dynamic and diverse perspectives on water governance and their willingness to respond to editorial requests. We also would like to thank the Editor-in-Chief George Tsakiris and the journal publisher, Springer, for kindly accepting our proposal for this Special Issue. Most importantly, we would like to acknowledge the efforts of Naomi Rubenstein, Research Assistant at the Monash Sustainability Institute, Monash University, for her assistance with managing the editorial process. 
Finally, we acknowledge the support of the National Climate Change Adaptation Research Facility (NCCARF) through the Water Resources and Freshwater Biodiversity Adaptation Research Network, of which we coordinate the Water Governance Theme (http://www.nccarf.edu.au/water/node/5). The objectives of this Water Governance Research Initiative are to create a community of conversation about water governance in Australia, build collaborative research links, create opportunities for co-researching and information sharing, and provide opportunities for early-career researchers to participate in a national network of researchers and research-users. With this Special Issue, we extend an invitation to participate in the network to any interested readers.

\section{References}

Bakker K (ed) (2007) Eau Canada: The future of Canada's water. UBC, Vancouver

Brown R, Ashley R, Farrelly M (2011) Political and professional agency entrapment: an agenda for urban water research. Water Resour Manage. doi:10.1007/s11269-011-9886-y

Collins KB, Ison RL (2009) Living with environmental change: adaptation as social learning. Editorial, Special Edition, Environmental Policy \& Governance 19:351-357

Collins KB, Ison RL (2010) Trusting emergence: some experiences of learning about integrated catchment science with the Environment Agency of England and Wales. Water Resour Manage 24:669-688

Connell DP (2011) Water reform and the federal system in the Murray-Darling Basin. Water Resour Manage. doi:10.1007/s11269-011-9897-8

De Stefano L (2010) International initiatives for water policy assessment: a review. Water Resour Manage 24:2449-2466

Foerster AC (2011) Developing purposeful and adaptive institutions for effective environmental water governance. Water Resour Manage. doi:10.1007/s11269-011-9879-x

Garnaut R (2011) The Garnaut review 2001: Australia in the global response to climate change. Cambridge University Press, New York

Godden L, Kung A (2011) Water law and planning frameworks under climate change variability: systemic and adaptive management of flood risk. Water Resour Manage. doi:10.1007/s11269-011-9887-x

Harris, E (2011) The impact of institutional path dependence on water market efficiency in Victoria, Australia. Water Resour Manage. doi:10.1007/s11269-011-9884-0

IPCC (International Panel on Climate Change) (2007) Climate Change 2007 Synthesis Report (see http:// www.ipcc.ch/publications_and_data/ar4/syr/en/contents.html Accessed 19th July 2011)

Ison RL, Collins KB, Colvin JC, Jiggins J, Roggero PP, Seddaiu G, Steyaert P, Zanolla C (2011) Sustainable catchment managing in a climate changing world: new integrative modalitites for connecting policy makers, scientists and other stakeholders. Water Resour Manage. doi:10.1007/s11269-011-9880-4

Molle F, Foran T, Kakonen M (eds) (2009) Contested waterscapes in the Mekong region: hydropower, livelihoods and governance. Earthscan, London

Mysiak J, Henrikson HJ, Sullivan C, Bromley J, Pahl-Wostl C (eds) (2010) The adaptive water resource management handbook. Earthscan, London

Pollard S, du Toit D (2011) Towards adaptive integrated water resources management in southern Africa: The role of self-organisation and multi-scale feedbacks for learning and responsiveness in the Letaba and Crocodile catchments, Water Resour Manage. doi:10.1007/s11269-011-9904-0

Sabatier PA, Focht W, Lubell M, Trachtenberg Z, Vedlitz A, Matlock M (eds) (2005) Swimming upstream. Collaborative approaches to watershed management. MIT, Cambridge

Tisdell JG (2009) Acquiring water for environmental use in Australia: an analysis of policy options. Water Resourc Manage 24:1515-1530

Wallis P, Ison RL (2011) Appreciating institutional complexity in water governance dynamics: a case from the Murray-Darling Basin, Australia. Water Resour Manage. doi:10.1007/s11269-011-9885-z

Wenger E (1998) Communities of practice. Cambridge University Press, Cambridge 